\title{
DECISION TREE CLOUD DETECTION ALGORITHM BASED ON FY-4A SATELLITE DATA
}

\author{
Zhuofu Yu, Weihua Ai*, Zhonghui Tan, Wei Yan \\ College of Meteorology and Oceanography, National University of Defense Technology, Nanjing, China - (yzffish, awhzjax, \\ tzh_go)@126.com,18913979082@163.com
}

Commission III, WG III /8

KEY WORDS: FY-4A, Cloud detection, Decision tree, on-board processing, Infrared, Visible light

\begin{abstract}
:
In order to study the on-board processing technology of meteorological satellites, a decision tree cloud detection algorithm is proposed by taking FY-4A satellite data as an example. According to the channel setting of the Advanced Geosynchronous Radiation Imager (AGRI) on FY-4A satellite, the $0.65 \mu \mathrm{m}, 1.375 \mu \mathrm{m}, 3.75 \mu \mathrm{m}$, and $10.7 \mu \mathrm{m}$ bands are selected as the cloud detection channels, and the reflectance, brightness temperature or bright temperature difference of the four channels are used as the cloud detection indicators, the thresholds of the four cloud detection indicators are obtained through statistics. On this basis, the decision tree cloud detection model is constructed and validated using FY-4A satellite data. The results show that the algorithm is simple, convenient and efficient, and the overall effect of cloud detection is good. It is an effective way for meteorological satellite cloud detection on-board processing technology.
\end{abstract}

\section{INTRODUCTION}

Cloud detection is a focus of research on atmospheric science. The precise result of cloud detection is helpful to grasp the development of weather situation, and plays an important role of analysing the change of climate. As the technology of satellites advances, the meteorological satellite is used widely. It becomes a usual way to use meteorological satellites to detect cloud. For different channels of the instruments on satellite, the reflectance and bright temperature of cloud are different from those of surface. Thus, cloud and surface can be distinguished by setting thresholds of reflectance and bright temperature on different channels, and the cloud can be detected by this way.

Many kinds of algorithms are put forward based on different instruments on satellites. Such as MODIS algorithm of cloud detection (Team M. C. M., 1997; Xie et al., 2018; Shi et al., 2009; Sheng et al., 2005; Tian et al., 2008; Keith et al., 2011; Steven et al., 1998; Takashi et al., 2011; Keith et al., 2010), ClAVR algorithm(Stowe et al., 1995) and APOLLO algorithm based on AVHRR(Kriebel et al., 2003), algorithm based on NWC/GEO developed by French Meteorological Agency, algorithm based on TRMM VIRS(Liu et al., 2010), algorithm based on AHI of Himawari-8(Shang et al., 2017), and algorithms based on FY-3C(Zhang et al., 2017), FY-3D(Jing, 2018), FY-2C(Liu et al., 2009), FY-2G(Fu et al., 2019) in China. The essence of these algorithms is using the thresholds of reflectance and bright temperature on visible light, infrared channels to detect cloud.

FY-4A is the second generation geostationary meteorological satellite of China and it was launched on December in 2016 ( Lu et al., 2017). The second generation geostationary meteorological satellite and its application technology are tested by use FY-4A. The data of channels on $0.65 \mu \mathrm{m}, 1.61 \mu \mathrm{m}$, $3.75 \mu \mathrm{m}, 7.1 \mu \mathrm{m}, 10.7 \mu \mathrm{m}, 12.0 \mu \mathrm{m}$ is used in the standard algorithm of cloud detection for FY-4A, in order to work out the cloud mask products (CLM), other auxiliary data is used (Wang and Shen, 2018). Gao et al used BP neural networks to get FY-4A cloud detection products, combined the data of 14 channels of AGRI on FY-4A.

These algorithms of cloud detection above are precise, but for on-board processing, these algorithms are complex, and they have used too many channels and too much data. As a result, they can not improve the transmission quality of satellite data and spectrum utilization, and can not meet the requirement on effectiveness (Yang, 2013). Thus, this article carries out cloud detection on-board processing technology research taking the data of FY-4A as an example, according to the theory of decision tree.

\section{DATA}

\subsection{Select Channels}

For selecting the proper channels to detect cloud, it is necessary to compare the channels of AGRI on FY-4A with the channels of MODIS used for detecting cloud and the channels of AVHRR used for detecting cloud, firstly.

There are 14 channels of AGRI on FY-4A and they are distributed in visible light and infrared bands. Table 1 shows the center wavelengths and ranges of the 14 bands.

\footnotetext{
* Corresponding author
} 


\begin{tabular}{cc}
\hline Range $(\mu \mathrm{m})$ & Center wavelength $(\mu \mathrm{m})$ \\
\hline $0.45-0.49$ & 0.47 \\
$0.55-0.75$ & 0.65 \\
$0.75-0.90$ & 0.825 \\
$1.36-1.39$ & 1.375 \\
$1.58-1.64$ & 1.61 \\
$2.1-2.35$ & 2.25 \\
$3.5-4.0$ & $3.75 \mathrm{H}$ \\
$3.5-4.0$ & $3.75 \mathrm{~L}$ \\
$5.8-6.7$ & 6.25 \\
$6.9-7.3$ & 7.1 \\
$8.0-9.0$ & 8.5 \\
$10.3-11.1$ & 10.7 \\
$11.5-12.5$ & 12.0 \\
$13.2-13.8$ & 13.5
\end{tabular}

Table 1. Range and center wavelength of each channel of AGRI on FY-4A

AVHRR is aboard on satellites of NOAA series and its channels are also distributed in visible light and infrared bands. Firstly, there are 4 channels on AVHRR, the advanced AVHRR/2 has 5 channels and the AVHRR/3 has 6 channels at present. The information of AVHRR is listed in Table 2.

\begin{tabular}{|c|c|c|c|c|c|}
\hline \multicolumn{2}{|c|}{ AVHRR } & \multicolumn{2}{|c|}{ AVHRR/2 } & \multicolumn{2}{|c|}{ AVHRR/3 } \\
\hline $\begin{array}{c}\text { Range } \\
(\mu \mathrm{m})\end{array}$ & $\begin{array}{l}\text { Center } \\
\text { wavelength } \\
\quad(\mu \mathrm{m})\end{array}$ & $\begin{array}{c}\text { Range } \\
(\mu \mathrm{m})\end{array}$ & $\begin{array}{c}\text { Center } \\
\text { wavelength } \\
\quad(\mu \mathrm{m})\end{array}$ & $\begin{array}{c}\text { Range } \\
(\mu \mathrm{m})\end{array}$ & $\begin{array}{l}\text { Center } \\
\text { wavelength } \\
\quad(\mu \mathrm{m})\end{array}$ \\
\hline \multirow[t]{3}{*}{$\begin{array}{c}0.55- \\
0.68\end{array}$} & 0.615 & $\begin{array}{c}0.55- \\
0.68\end{array}$ & 0.615 & & \\
\hline & & & & $\begin{array}{c}0.58- \\
0.68\end{array}$ & 0.63 \\
\hline & & & & $\begin{array}{c}0.725- \\
1.00\end{array}$ & 0.862 \\
\hline \multirow[t]{2}{*}{$\begin{array}{c}0.725- \\
1.10\end{array}$} & 0.912 & $\begin{array}{c}0.725- \\
1.10\end{array}$ & 0.912 & & \\
\hline & & & & $\begin{array}{c}1.58- \\
1.64\end{array}$ & 1.61 \\
\hline \multirow[t]{2}{*}{$\begin{array}{l}3.55- \\
3.93\end{array}$} & 3.74 & $\begin{array}{l}3.55- \\
3.93\end{array}$ & 3.74 & $\begin{array}{c}3.55- \\
3.93\end{array}$ & 3.74 \\
\hline & & $\begin{array}{c}10.3- \\
11.3\end{array}$ & 10.8 & $\begin{array}{c}10.3- \\
11.3\end{array}$ & 10.8 \\
\hline \multirow[t]{2}{*}{$\begin{array}{c}10.5- \\
11.5\end{array}$} & 11.0 & & & & \\
\hline & & $\begin{array}{l}11.5- \\
12.5\end{array}$ & 12.0 & $\begin{array}{l}11.5- \\
12.5\end{array}$ & 12.0 \\
\hline
\end{tabular}

Table 2. Range and center wavelength of each channel on AVHRR, AVHRR/2, AVHRR/3
There are 36 channels on MODIS boarded on Terra and Aqua. It is explained that the channels for cloud detection include 1, 2, $4,5,6,7,17,18,19,20,22,23,26,27,28,29,31,32,33$, and 35 in algorithm document of MOD35 products in detail. Table 3 lists the information of all channels above.

\begin{tabular}{|c|c|c|c|c|c|}
\hline Band & $\begin{array}{l}\text { Range } \\
(\mu \mathrm{m})\end{array}$ & $\begin{array}{c}\text { Center } \\
\text { wavelength } \\
(\mu \mathrm{m})\end{array}$ & Band & $\begin{array}{l}\text { Range } \\
(\mu \mathrm{m})\end{array}$ & $\begin{array}{c}\text { Center } \\
\text { wavelength } \\
(\mu \mathrm{m})\end{array}$ \\
\hline 1 & $\begin{array}{c}0.620- \\
0.670\end{array}$ & 0.645 & 22 & $\begin{array}{c}3.929 \\
- \\
3.989\end{array}$ & 3.959 \\
\hline 2 & $\begin{array}{c}0.841- \\
0.876\end{array}$ & 0.858 & 23 & $\begin{array}{c}4.020- \\
4.080\end{array}$ & 4.050 \\
\hline 4 & $\begin{array}{c}0.545- \\
0.565\end{array}$ & 0.555 & 26 & $\begin{array}{c}1.360- \\
1.390\end{array}$ & 1.375 \\
\hline 5 & $\begin{array}{c}1.230- \\
1.250\end{array}$ & 1.240 & 27 & $\begin{array}{c}6.535- \\
6.895\end{array}$ & 6.715 \\
\hline 6 & $\begin{array}{l}1.628- \\
1.652\end{array}$ & 1.640 & 28 & $\begin{array}{l}7.175- \\
7.475\end{array}$ & 7.325 \\
\hline 7 & $\begin{array}{l}2.105- \\
2.135\end{array}$ & 2.130 & 29 & $\begin{array}{c}8.400- \\
8.700\end{array}$ & 8.550 \\
\hline 17 & $\begin{array}{c}0.890- \\
0.920\end{array}$ & 0.905 & 31 & $\begin{array}{c}10.78- \\
11.28\end{array}$ & 11.030 \\
\hline 18 & $\begin{array}{c}0.931- \\
0.941\end{array}$ & 0.936 & 32 & $\begin{array}{l}11.77- \\
12.27\end{array}$ & 12.020 \\
\hline 19 & $\begin{array}{c}0.915- \\
0.965\end{array}$ & 0.940 & 33 & $\begin{array}{c}13.18 \\
5- \\
13.48 \\
5\end{array}$ & 13.335 \\
\hline 20 & $\begin{array}{c}3.660- \\
3.840\end{array}$ & 3.750 & 35 & $\begin{array}{c}13.78 \\
5- \\
14.08 \\
5\end{array}$ & 13.935 \\
\hline Table 3 & & $\begin{array}{l}\text { nter wavele } \\
\text { DIS for clou }\end{array}$ & $\begin{array}{l}\mathrm{h} \text { of e } \\
\text { etecti }\end{array}$ & chann & ised by \\
\hline \multicolumn{6}{|c|}{$\begin{array}{l}\text { Combined MODIS algorithm of cloud detection and the } \\
\text { standard algorithm of cloud detection for FY- } 4 \mathrm{~A} \text {, the } 0.65 \mu \mathrm{m} \text {, } \\
1.375 \mu \mathrm{m} 、 3.75 \mu \mathrm{m} 、 10.7 \mu \mathrm{m} \text { bands are selected as the channels } \\
\text { to detect cloud according to the principle that the center } \\
\text { wavelengths and the range of bands are close. At the same time, } \\
\text { R0.65 (reflectance of } 0.65 \mu \mathrm{m} \text { channel), R1.375 (reflectance of } \\
1.375 \mu \mathrm{m} \text { channel), BT10.7 (bright temperature of } 10.7 \mu \mathrm{m} \\
\text { channel), and BT10.7-BT3.75 (bright temperature difference } \\
\text { between } 10.7 \mu \mathrm{m} \text { channel and } 3.75 \mu \mathrm{m} \text { channel) are selected as } \\
\text { the indicators for cloud detection. }\end{array}$} \\
\hline
\end{tabular}

For determining the thresholds of four cloud detection indicators, the influence of surface types is not taken into consideration. Thus, the area selected for research is located in $115^{\circ} \mathrm{E}-120^{\circ} \mathrm{E}, 29^{\circ} \mathrm{N}-34^{\circ} \mathrm{N}$. The area is low in altitude and is located in the plains.

The horizontal resolution of the data that is used in the research is $4 \mathrm{~km}$. There are 11937 scanning points of AGRI in this area. At every point, the reflectance, bright temperature and CLM products of FY-4A can be acquired. The values of CLM products are $0,1,2,3$ and that respectively mean cloud, probably cloud, probably clear, clear. 
Four cloud detection indicators are analysed by doing statistics on CLM products of 3 months from UCT 00 to UTC 07 every day from September to November in 2017. The distribution of 4 indicators is shown in 4 figures below.

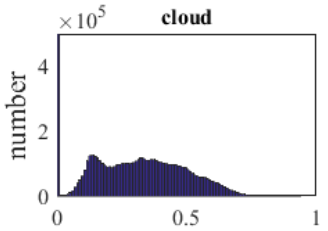

a

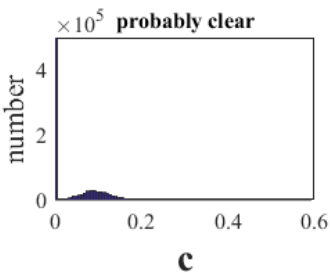

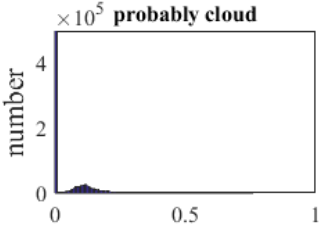

b

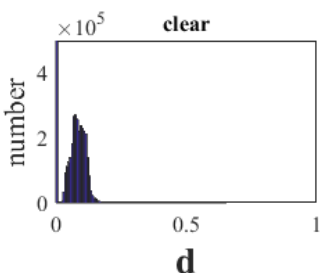

Figure 1. The numerical distribution of R0.65. Figures a, b, c, and $\mathrm{d}$ are the numerical distributions of R0.65 in the case of "cloud", "probably cloud", "probably clear", and "clear".
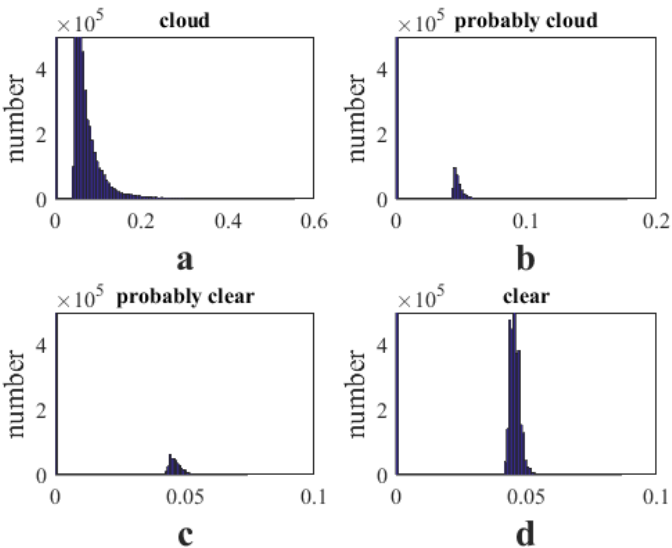

Figure 2. The numerical distribution of R0.1.375. Figures a, b, c, and $\mathrm{d}$ are the numerical distributions of R1.375 in the case of "cloud", "probably cloud", "probably clear", and "clear".
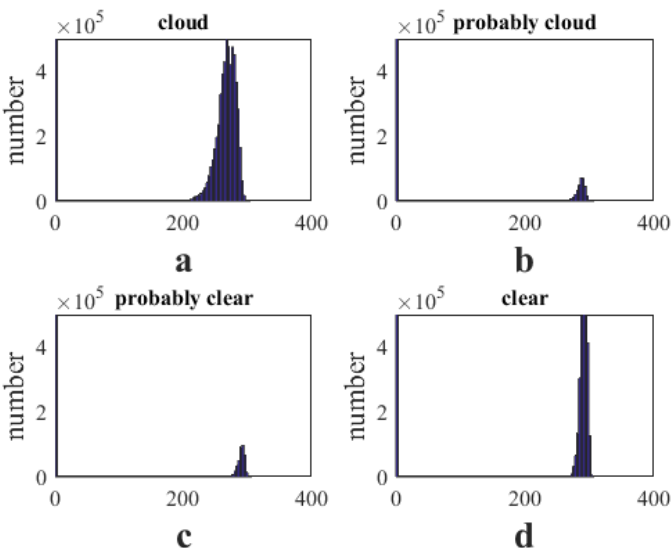

Figure 3. The numerical distribution of BT10.7. Figures a, b, c, and $\mathrm{d}$ are the numerical distributions of BT10.7 in the case of "cloud", "probably cloud", "probably clear", and "clear".
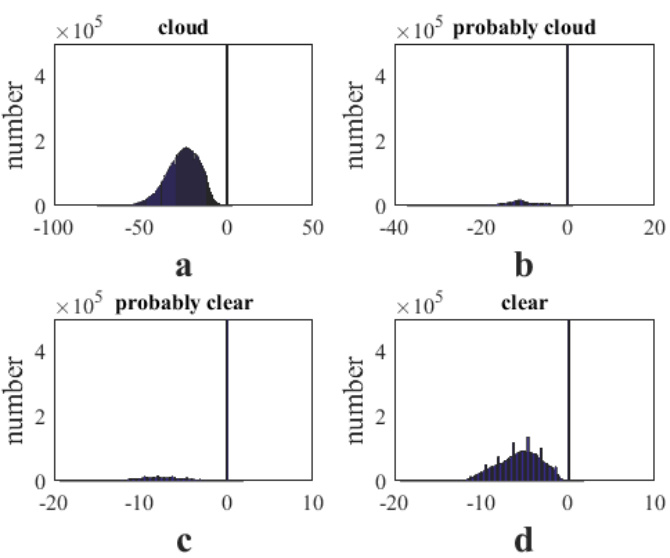

Figure 4. The numerical distribution of BT10.7-BT3.75. Figures $\mathrm{a}, \mathrm{b}, \mathrm{c}$, and $\mathrm{d}$ are the numerical distributions of BT10.7-BT3.75 in the case of "cloud", "probably cloud", "probably clear", and "clear".

According to the distribution, the thresholds of four indicators can be determined, the results are listed in Table 4.

\begin{tabular}{ccc}
\hline Indicators & $\begin{array}{c}\text { Thresholds of } \\
\text { cloud }\end{array}$ & Thresholds of clear \\
\hline R0.65 & $>0.190$ & $<0.140$ \\
R1.375 & $>0.050$ & $<0.048$ \\
BT10.7 & $<273$ & $>285$ \\
BT10.7-BT3.75 & $<-10.5$ & $>-9.2$ \\
\hline
\end{tabular}

Table 4. Cloud detection thresholds for four indicators

\subsection{Process Data}

In combination with the cloud detection indicators selected in 2.1 and the thresholds determined in 2.2 , the data on each scanning point in the study area is processed. In the process, the confidence $(\boldsymbol{C})$ is introduced to determine the result of cloud detection. The way to calculate confidence refers to the MODIS algorithm of cloud detection, and the calculation formula is shown below.

When bright temperature or bright temperature difference is used to calculate confidence, the formula 1 is adopted.

$$
C=\left\{\begin{array}{cl}
0, & x<a \\
\frac{x-a}{2(b-a)}, & a \leq x<b \\
1-\frac{x-c}{2(b-c)}, & b \leq x<c \\
1, & c \leq x
\end{array}\right.
$$

In formula $1, \mathrm{x}$ is bright temperature or bright temperature difference, $a$ is the threshold of cloud, $c$ is the threshold of clear and $b$ is the mean value of $a$ and $c$.

When reflectance is used to calculate confidence, the formula 2 is adopted. 


$$
C=\left\{\begin{array}{cl}
1, & x<a \\
\frac{x-a}{2(b-a)}, & a \leq x<b \\
1-\frac{x-c}{2(b-c)}, & b \leq x<c \\
0, & c \leq x
\end{array}\right.
$$

In formula 2, $\mathrm{x}$ is reflectance, $a$ is the threshold of clear, $c$ is the threshold of cloud and $b$ is the mean value of $a$ and $c$

Table 5 shows the correspondence between confidence and cloud detection results.

\begin{tabular}{cc}
\hline Confidence & Cloud detection results \\
\hline $0 \leq C<0.66$ & cloud (expressed by 0) \\
$0.66 \leq C<0.95$ & probably cloud \\
(expressed by 1) \\
$0.95 \leq C<0.99$ & probably clear \\
$0.99 \leq C<1$ & (expressed by 1) \\
clear (expressed by 3) \\
\hline
\end{tabular}

Table 5. Correspondence between confidence and cloud detection results

On each scanning point, the cloud detection result, which can be used as samples while the CLM products on each scanning point can be used as true value, can be acquired by process four indicators according to the above method. The data for UTC 0007 every day from September to November 2017 can be processed to training dataset, and the data for UTC 00-07 every day from September to November 2018 can be processed to validation dataset.

\section{DECISION TREE CLOUD DETECTION ALGORITHM}

\subsection{Decision Tree Algorithm}

Decision tree algorithm is a machine learning algorithm mainly used to deal with classification problems and regression problems. The key of the algorithm is to select the attributes of decision tree and the attribute of decision tree is the feature of samples. Samples of different kinds perform differently on all kinds of features. The essence of this algorithm is to solve classification problems and regression problems by analysing the performance of samples on all kinds of features. It is the principle of selecting attributes to make samples of different kinds perform differently as possibly as they can and samples of same kinds perform same as possibly as they can. For evaluating the difference of all kinds of samples quantitatively, the Information Entropy and Gini index are introduced, the definitions of the two are as follows:

In dataset $\mathrm{Z}$, there are $\mathrm{n}$ kinds of samples. The samples of class $\mathrm{i}$ hold proportion of $p_{i}$ in dataset $Z$., the definition of the entropy of dataset $\mathrm{Z}$ is shown by formula 3 :

$$
\operatorname{Entropy}(Z)=-\sum_{i=1}^{n} p_{i} \log _{2} p_{i}
$$

The smaller the value of entropy of dataset $Z$, the difference among samples of different kinds is more obvious and the purity of samples of the same kinds is higher.

The definition of the Gini index of dataset $\mathrm{Z}$ is shown by formula 4:

$$
\operatorname{Gini}(Z)=\sum_{i=1}^{n} \sum_{j \neq i} p_{i} p_{j}=1-\sum_{i=1}^{n} p_{i}^{2}
$$

The smaller the value of Gini index of dataset $Z$, the difference among samples of different kinds is more obvious and the purity of samples of the same kinds is higher (Zhou, 2016).

When decision tree is constructed, to choose criteria for the classification is the first step, it can be information entropy or Gini index. And to classify the samples according to the performance of samples on attributes of decision tree is the second step. In process of classification, one attribute of decision tree is selected as the feature to classify samples each time. After all attributes have been selected following the importance of attributes, the final decision tree have been formed.

\subsection{Process of Decision Tree Cloud Detection}

Decision tree cloud detection algorithm proposed by us is multichannels thresholds algorithm in essence. Firstly, proper bands of AGRI on FY-4A are selected as cloud detection channels and the data of channels selected is cloud detection indicator. Secondly, thresholds of all indicators are determined by doing statistics on CLM products. Thirdly, training dataset and validation dataset are formed by processing data of selected channels. Finally, decision tree cloud detection model is constructed by using training dataset and validated by validation dataset. The algorithm establishes a simple and effective cloud detection process. Compared with other cloud detection algorithms, this algorithm improves the efficiency of cloud detection. Figure 5 shows the process. 


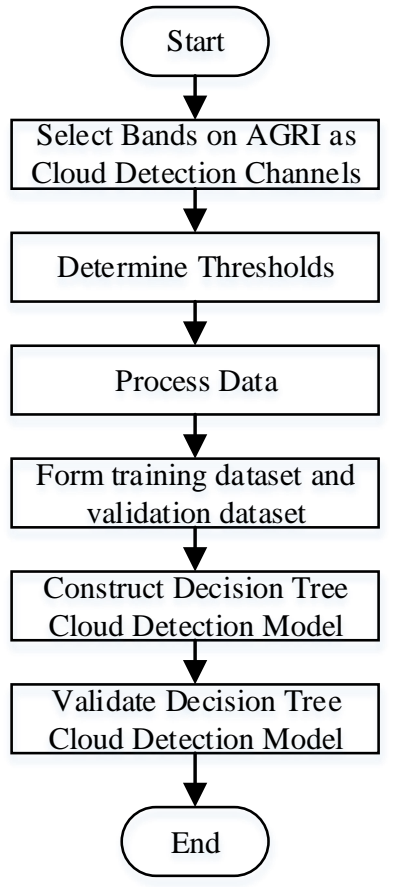

Figure 5. Flowchart of decision tree cloud detection algorithm

In decision tree cloud detection algorithm proposed by us, the four cloud detection indicators selected in 1.1 are used as attributes of decision tree. Two decision tree models are constructed respectively by using Information entropy and Gini index as classification criteria.

\section{RESULT}

\subsection{Construct Decision Tree Cloud Detection Model}

On the basis of data process in 1.3 , decision tree cloud detection model is constructed by using training dataset. In order to avoid overfitting problem, the training samples are extracted randomly, the depth of decision tree is set to ten and the minimum number of classified samples for a node is 200 .

Firstly, model is constructed by using information entropy as classification criteria. The accuracy of model is $90 \%$ by training. The comparison between models detection result and cloud detection true value is shown by Figure 6, and the specific information is listed in Table 6 .

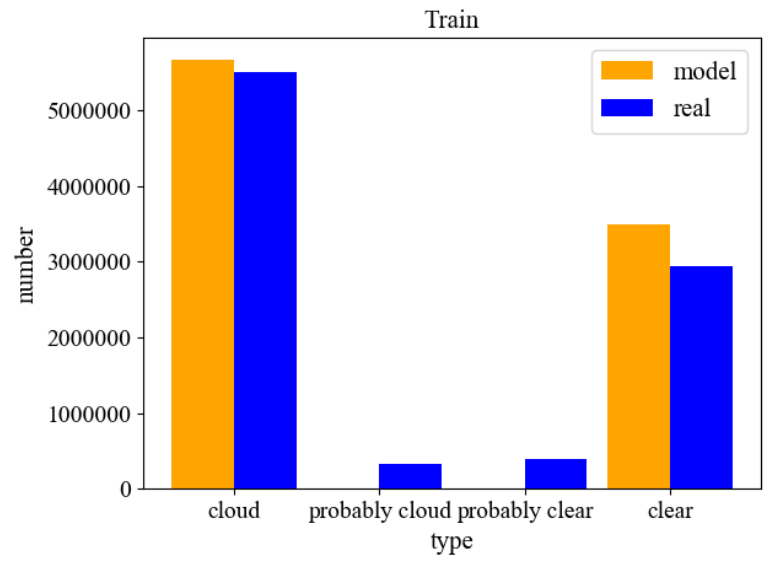

Figure 6. Model cloud test results and true values on training dataset.

\begin{tabular}{ccc}
\hline $\begin{array}{c}\text { Cloud } \\
\text { detection } \\
\text { results }\end{array}$ & $\begin{array}{c}\text { Models detection } \\
\text { result } \\
\text { (number of } \\
\text { scanning points) }\end{array}$ & $\begin{array}{c}\text { True value } \\
\text { (number of } \\
\text { scanning points) }\end{array}$ \\
\hline cloud & 5669496 & 5494395 \\
probably cloud & 3670 & 332833 \\
probably clear & 188 & 386286 \\
clear & 3494262 & 2942165 \\
\hline
\end{tabular}

Table 6. Model cloud test results and true values on training dataset

The importance of attributes in model is expressed by weight of attributes and weight value depends on the extent of improved purity of all kinds of samples after classified according to this attribute. The more obviously the purity improved, the weight value of the attribute is larger. Weights of all attributes are shown in Table 7.

\begin{tabular}{cc}
\hline Attributes & Weight value \\
\hline R0.65 & 0.057 \\
R1.375 & 0.018 \\
BT10.7 & 0.785 \\
BT10.7-BT3.75 & 0.140 \\
\hline
\end{tabular}

Table 7. Weight of each attribute in the model when the information entropy is used as a criterion

Secondly, model is constructed by using Gini index as classification criteria. The results of training are the same as those acquired by training using information entropy as classification criteria. But the weight values of four attributes are different, Table 8 shows the weight value.

\begin{tabular}{cc} 
Attributes & Weight value \\
\hline R0.65 & 0.059 \\
R1.375 & 0.011 \\
BT10.7 & 0.861 \\
BT10.7-BT3.75 & 0.069
\end{tabular}

Table 8. Weight of each attribute in the model when the Gini index is used as a criterion

The results above indicates that the overall effect of the two models on the training set is good but there exists some difference between detection and true value for 'probably cloud' and 'probably clear'. The weight values of four attributes are different in two models. However, the order of importance of attributes is the same, in order BT10.7, BT10.7-BT3.75, $\mathrm{R} 0.65, \mathrm{R} 1.375$.

\subsection{Validate Decision Tree Cloud Detection Model}

Models are validated by using validation dataset of 2018 . The results of two models are the same. The accuracies of two models both are $86.4 \%$ on validation dataset. The comparison between models detection result and cloud detection true value is shown by Figure 7, and the specific information is listed in Table 9. 


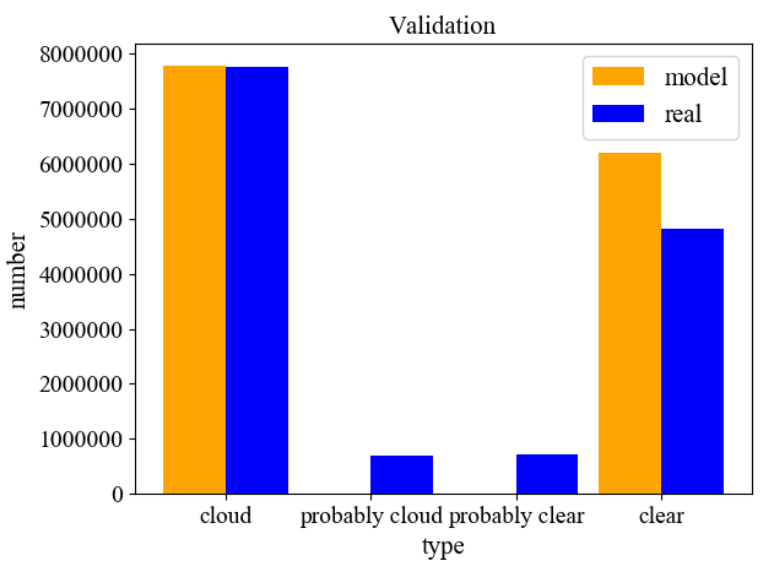

Figure 7. Model cloud test results and true values on verification dataset

\begin{tabular}{ccc}
\hline $\begin{array}{c}\text { Cloud } \\
\text { detection } \\
\text { results }\end{array}$ & $\begin{array}{c}\text { Models detection } \\
\text { result } \\
\text { (number of } \\
\text { scanning points) }\end{array}$ & $\begin{array}{c}\text { True value } \\
\text { (number of } \\
\text { scanning points) }\end{array}$ \\
\hline cloud & 7787193 & 7756052 \\
probably cloud & 14368 & 688656 \\
probably clear & 0 & 719700 \\
clear & 6188603 & 4825756 \\
\hline
\end{tabular}

Table 9. Model cloud test results and true values on validation dataset

The above results show that comparing with training results, the accuracies of two models decreases on validation dataset. However, the accuracies of two models still keep higher than $85 \%$, and it can prove that the algorithm proposed by us is reasonable.

\subsection{Case Analysis}

In order to show the effect of this algorithm, three cases are analysed. The three cases are UTC 0615 , on September 17, 2018, UTC 0000, on October 5, 2018 and UTC 0700, November 19, 2018, which corresponds "cloud" area occupying most of the research area, "clear" area occupying most of the research area, and "cloud" area, "clear" area basically occupy half of the research area. As consequence of two models perform same on training dataset and validation dataset, in following analysis, the first model that is formed using information entropy as classification criteria is analysed to represent the algorithm. Three cases are shown in Figure 8, 9 and 10.
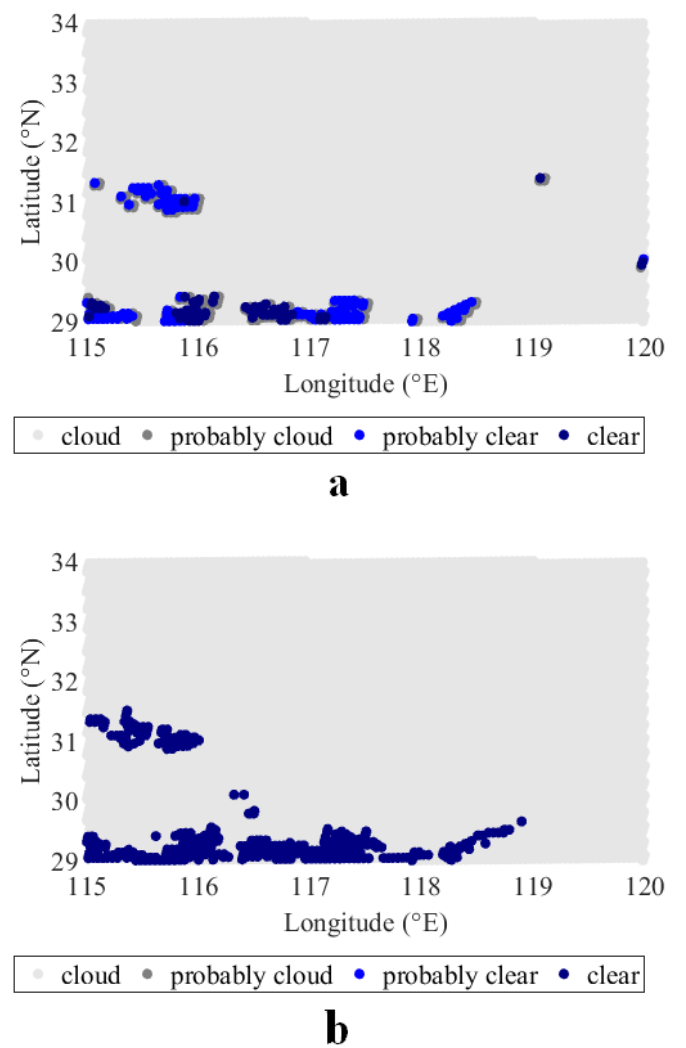

Figure 8. Cloud detection image at UTC 20180917061500. Figure $\mathrm{a}$ is the CLM product of FY-4A, and Figure $\mathrm{b}$ is the detection result of the decision tree cloud detection model.

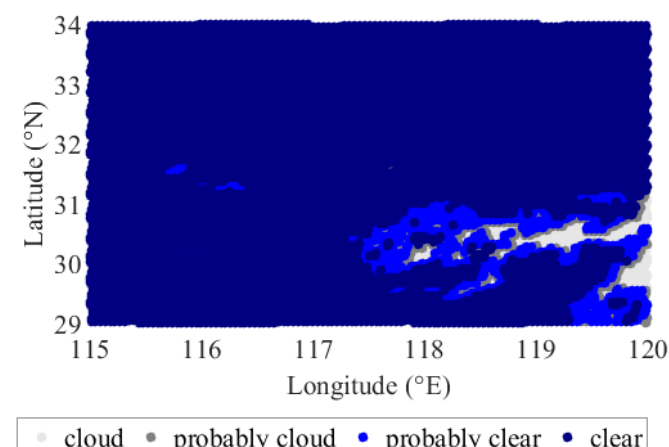

a

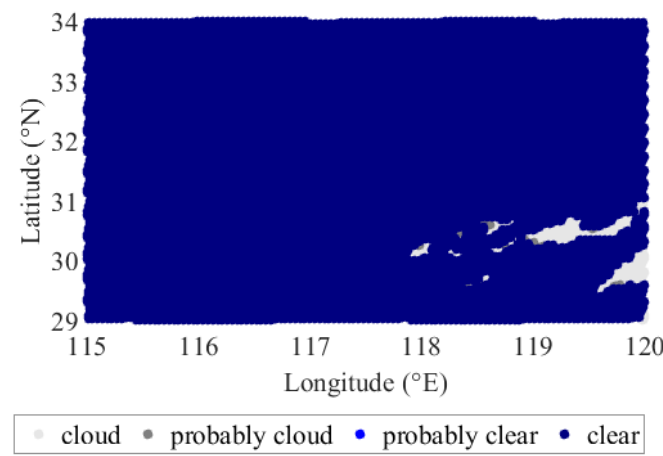

b

Figure 9. Cloud detection image at UTC 20181005000000. Figure $a$ is the CLM product of FY-4A, and Figure $b$ is the detection result of the decision tree cloud detection model. 


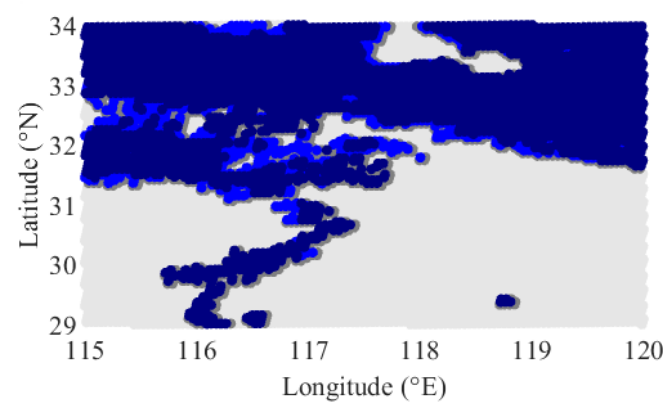

cloud $\bullet$ probably cloud $\bullet$ probably clear $\bullet$ clear

a

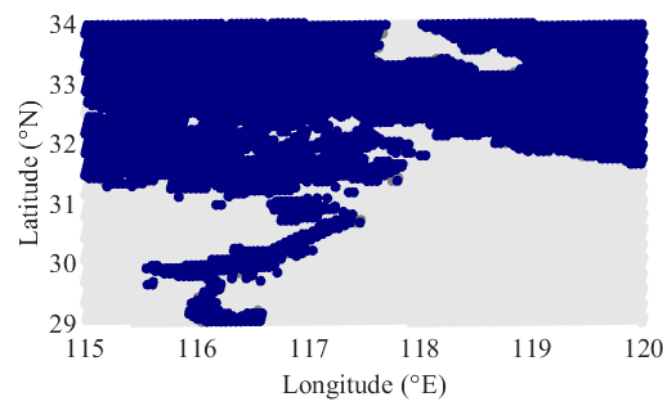

cloud $\bullet$ probably cloud $\bullet$ probably clear $\bullet$ clear

\section{b}

Figure 10. Cloud detection image at UTC 20181119070000. Figure $a$ is the CLM product of FY-4A, and Figure $b$ is the detection result of the decision tree cloud detection model.

In order to evaluate the detected effect of the three cases quantitatively, the effect is scored on 11937 scanning points in research area. If the detected result is the same as true value, the score on the scanning points is 1 , otherwise it is 0 . The total score on all scanning points is divided by the total number of scanning points as the accuracy of the model cloud detection. The detection effect is shown in Table 10.

\begin{tabular}{ccc}
\hline Cases & Score & Accuracy \\
\hline $\begin{array}{c}\text { UTC 0615, } \\
\text { September 17, 2018 } \\
\text { UTC 0000, } \\
\begin{array}{c}\text { October 5, 2018 } \\
\text { UTC 0700, } \\
\text { November 19, 2018 }\end{array}\end{array}$ & 11479 & 0.9616 \\
\hline Tabe 10. & 10579 & 0.8862 \\
\hline
\end{tabular}

Table 10. Detection results of three cases

The three cases shows that the results of the decision tree cloud detection model in research area are consistent with the CLM products of FY-4A on the overall trend. The accuracies of three cases are all above $85 \%$ for the model.

\subsection{Evaluate the Efficiency of the Algorithm}

In order to meet the requirements of on-board processing technology for efficiency, the algorithm not only must guarantee high accuracy, but also must be simple and convenient. Thus, the amount of data and calculating time are analysed to evaluate the efficiency of the algorithm.
Four channels of AGRI on FY-4A are used in the algorithm proposed by us. When using level 1 data of four channels at a certain time to detect cloud, the data volume is $29 \%$ of the full level 1 data and no more than $34 \mathrm{M}$. The time of the process that data input to model and model running is no more than 1 s on a computer with 4G RAM and CPU for Intel i7-3770. Taking limitation of hardware and software of on-board processing technology into consideration at present, in terms of the above analysis to data volume and model running time, the algorithm proposed by us fulfils the requirement of on-board processing technology

\section{CONCLUSION}

A decision tree cloud detection algorithm is proposed based on FY-4A data, which can be an effective way of meteorological satellite cloud detection on-board processing technology. Firstly, according to the channel setting of AGRI on FY-4A, four cloud detection channels are selected. The reflectance, bright temperature or bright temperature difference of these four channels are used as cloud detection indicators, and the thresholds of four cloud detection indicators are acquired by statistical methods. On this basis, combined with the theory and method of decision tree, level 1 data of FY-4A and cloud detection products are used to construct and validate the decision tree cloud detection model.

Overall, the algorithm has a good cloud detection effect. Compared with the FY-4A cloud detection product, the accuracy of the algorithm can reach more than $85 \%$. However, Apart from training samples are not so adequate that form a better model, the insufficient training of the model and the problem that the accuracy of the cloud detection indicators thresholds needs to be further improved are also lead that the detection effect of the algorithm on "probably clear" and "probably cloud" needs to be improved.

The algorithm is evaluated from two aspects: data volume and running time. From the evaluation results, the algorithm proposed by us uses a small amount of data, and the algorithm runs efficiently, meeting the requirements of on-board processing technology. Compared with the current common cloud detection algorithm, the algorithm is simple and convenient. It is an effective way for meteorological satellite cloud detection on-board processing technology, which helps to improve the efficiency of satellite data processing and the level of meteorological support services.

\section{ACKNOWLEDGEMENTS}

Acknowledgements of support for the FY-4A data and technical documents provided by the National Satellite Meteorological Center.

\section{REFERENCES}

Team, M. C. M., Ackerman, S., Strabala, K., et al., 1997. Discriminating clear-sky from cloud with MODIS algorithm theoretical basis document (mod35). ATBD Ref. ATBD-MOD06, version ATBD Ref. ATBD-MOD-06, version, 4:115p.

Xie, B. J., Ma, H., Liu, G. Z., 2018. Study of cloud detection method in the Yellow and Bohai Seas based on MODIS data. Marine Sciences, 42(3):17-22. 
Shi, H. Q., Wang, Y., Liu, X. P., 2009. Research on cloud detection method based on MODIS data in southeast coastal area of China: The 5th Symposium on Atmospheric Exploration, Environmental Remote Sensing and Electronic Technology in Jiangsu and Anhui in 2009. Yangzhou: Jiangsu Meteorological Society , 2009:358-363.

Sheng, X., Li, W., Sun, L. X., 2005. MODIS image cloud detection algorithm based on unsupervised clustering and decision tree: The 15th National Remote Sensing Technology Academic Exchange Conference. Guiyang, 2005:124.

Tian, X. L., Yang, Z., Xie, B., 2008. Implementation of a cloud detection method based on satellite image: 2008' China Information Technology and Application Academic Forum. Chengdu: Computer Science, 2008:244-245.

Keith, D. H., Barbara, D. I., Bruce, H., 2011. The use of global synthetic data for pre-launch tuning of the VIIRS cloud mask algorithm. International Journal of Remote Sensing, 33(5): 1400-1423.

Steven, A. A., Kathleen, I. S., W. Paul, M., et al., 1998. Discriminating clear sky from clouds with MODIS. Journal of Geophysical Research, 103(24D):32141-32157.

Takashi, Y. N., Takumi, T., Haruma, I., et al., 2011. Cloud detection performance of spaceborne visible-to-infrared multispectral imagers. Applied Optics, 50(17):2601-2616.

Keith, D. H., Bruce, H., Barbara, D., et al., 2010. Differentiating between clouds and heavy aerosols in Sun-Glint regions. Journal of Atmospheric and Oceanic Technology, 27(6):1085 - 1094

Stowe, L. L., Davis, P. A., McClain, E. P., 1995. Evaluating the CLAVR (clouds from AVHRR) phase I-cloud cover experimental product III . Advances in Space Research, 16(10):21-24.

Kriebel, K. T., Gesell, G., Kastner, M., et al., 2003. The cloud analysis tool APOLLO : improvements and validations. International Journal of Remote Sensing, 24(12):2389-2408.

Algorithm theoretical basis document for the cloud product processors of the NWC/GEO. http://www.nwcsaf.org/en/web/guest/aemetwebcontents/scientif icdocumentation/biasbt/biasbt_v2016_msg1_iodc/pge00p/scient ificdocumentationdown_bias_pge00p_msg1_iodc.html.

\#NWCSAF/MSG Basic Documents.

Liu, X. T., Liu, Q., Fu, Y. F., et al., 2010. Daytime cloud detection scheme relying on five-channel measurements from TRMM VIRS. Journal of Atmospheric and Environmental Optics, 5(2):128-140.

Shang, H. Z, Chen, L. F., Letu, H., et al., 2017. Development of a daytime cloud and haze detection algorithm for Himawari-8 satellite measurements over central and eastern China. Journal of Geophysical Research: Atmospheres, 122:3528-3543.

Zhang, S. L., Dai, H. S., Zhao, Q. C., et al., 2017. Cloud detection algorithm for FY-3C/MERSI. Ecology and Environmental Monitoring of Three Gorges, 2(4):66-70.
Jing, C. 2018. A study on cloud detection algorithm of FY-3D spectral imager over land. Nanjing: Nanjing University of Information Science \& Technology.

Liu, X. P., Wang. Y., Shi. H, Q., 2009. Research on cloud detection method based on FY-2C data: The 5th Symposium on Atmospheric Exploration, Environmental Remote Sensing and Electronic Technology in Jiangsu and Anhui in 2009, 2009. Yangzhou: Jiangsu Meteorological Society, 2009:355-358.

Fu, H. L., Feng, J., Li, J., et al., 2019. Cloud detection method of FY-2G satellite images based on random forest. Bulletin of Surveying and Mapping, 3:61-66.

Lu, F., Zhang, X. H., Chen, B. Y., et al., 2017. FY-4 geostationary meteorological satellite imaging characteristics and its application prospects. Journal of Marine Meteorology, 37(2): 1-12.

Wang, G. Q., Shen, X., 2018. The FY-4 radiometer imager and the application of its data in the satellite meteorology. Chinese Journal of Nature, 40(1):1-11.

Gao, J., Wang, K., Tian, X. Y., et al., 2018. A BP-NN based cloud detection method for FY-4 remote sensing images. Journal of Infrared and Millimeter Waves, 37(4):477-485.

Yang, Y., Tian, H. X., Tian, B., et al., 2013. On-board nonregenerating processing and stored program controlled switching and its possibility of supporting IP services. Journal of Signal Processing, 29(11):1555-1559.

Zhou, Z. H., 2016. Machine learning. Tsinghua University Press, Beijing, 75-79. 